\title{
O uso de expressões nominais no artigo de opinião
}

\section{The usage of nominal expressions in opinion pieces}

Cínthia Cardoso de Siqueira é especialista em Docência de Língua Portuguesa pelo Instituto Superior de Educação Vera Cruz (ISE Vera Cruz), bacharel e licenciada em Letras. Trabalha como professora de língua portuguesa na rede particular de ensino de São Paulo há dez anos e é autora do livro didático Letramento e alfabetização: $1^{\circ}$ ano, da Editora IBEP.

\section{Resumo}

Este estudo buscou investigar a maneira pela qual se dá o processo de referenciação construído pelo emprego de expressões nominais em artigos de opinião, com o objetivo de apontar alternativas didáticas para o ensino de língua portuguesa. 0 corpus analisado foi composto por um conjunto de artigos de opinião que circularam na grande imprensa em torno de temas diferentes, com o propósito de investigar se a temática interferiria nas funções cognitivodiscursivas assumidas pelas expressões nominais. Baseandose em estudos desenvolvidos no campo da linguística textual, a análise do corpus foi realizada tanto de forma quantitativa, quanto qualitativa, de modo a permitir a investigação da recorrência das expressões nominais referenciais em artigos de opinião e, também, das funções cognitivo-discursivas por elas desempenhadas. Os resultados indicaram que as expressões nominais não só são recorrentes em artigos de opinião, como desempenham diferentes funções cognitivodiscursivas em um mesmo texto, tornando-se uma efetiva estratégia para a construção textual dos sentidos. Palavras-chave: expressões nominais; gramática funcional; linguística textual; coesão textual; referenciação.

\section{Abstract}

This study researches how nominal expressions interfere in the referentiation process built from the application of 
nominal expressions in opinion pieces, with the purpose of appointing teaching options for Brazilian Portuguese. The corpus assessed was composed by opinion pieces propagated in the press concerning different themes to investigate if theme could interfere with cognitive-discursive functions of nominal expressions. Based on Text Linguistics studies, the corpus analysis has been conducted on both quantitative and qualitative data perspectives, to verify the recurrence of nominal expressions, and the cognitivediscursive functions they perform. The results pointed out that nominal expressions are not only recurring, but also play different cognitive-discursive functions in the same text, which makes their usage an effective strategy for the construction of textual meanings.

Keywords: nominal expressions; functional grammar; text linguistics; cohesion; referentiation.

\section{Introdução}

Muito se tem falado e discutido sobre o ensino da gramática nos últimos anos, e parece-nos que, em geral, os professores de língua portuguesa concordam que a gramática ensinada deva servir para que os alunos se expressem melhor. Entretanto, parece-nos também que algumas metodologias de ensino da gramática ainda não atendem a esse objetivo, apoiando-se em uma perspectiva meramente morfológica e sintática que tem como foco a análise da palavra e da frase.

Neves (2001, p. 65) afirma que, "se o ensino da gramática visa, pois, ao uso da língua, é perfeitamente previsível que o tratamento predominantemente formal que vem sendo dado à exercitação gramatical em sala de aula não cumpra seu papel". Nesse sentido, a autora propõe que a análise linguística em nível escolar baseiese em uma visão funcionalista, permitindo aos alunos uma melhor operacionalização dos conteúdos estudados. Essa abordagem sugere o estudo da língua em uso, analisando as correlações que se estabelecem entre classes, relações e funções da língua e as situações sociais concretas em que foram geradas; para tanto, é necessário considerar o texto como unidade mínima de estudo, não se realizando mais a análise de palavras, frases ou períodos descontextualizados.

Assim sendo, no processo de ensino-aprendizagem da língua, faz-se necessário entender a "atividade da linguagem 
como processo discursivo e interacional" (Antunes, 2009, p. 1). Baseamo-nos, pois, nos princípios da linguística textual, que abrange não só os elementos linguísticos, mas também os elementos cognitivos que contribuem para a construção textual do sentido.

A linguística textual pode ser definida como o "estudo das operações linguísticas e cognitivas reguladoras e controladoras da produção, construção, funcionamento e recepção de textos escritos ou orais" (Marcuschi, 1983 apud Koch, 2008, p. 10). Tal definição evidencia a relação entre os estudos desenvolvidos nessa área e o ensino da gramática em uma perspectiva funcionalista, considerando-se coerente que o texto passe a ser visto como unidade básica na análise da língua, tal como afirma Koch (2008, p. 11):
A Linguística Textual toma, pois, como objeto particular de investigação não mais a palavra ou a frase isolada, mas o texto, considerado a unidade básica de manifestação da linguagem, visto que o homem se comunica por meio de textos e que existem diversos fenômenos linguísticos que só podem ser explicados no interior do texto. 0 texto é muito mais que a simples soma das frases (e palavras) que o compõem: a diferença entre frase e texto não é meramente de ordem quantitativa; é sim de ordem qualitativa.

Assim, considerando o texto "um ato de comunicação unificado num complexo universo de ações humanas" (Marcuschi, 1983 apud Koch, 2008, p. 11), a linguística textual ocupa-se da investigação dos critérios ou princípios responsáveis pela textualidade, definida como "o que faz com que um texto seja um texto" (Koch, 2004, p. 29). Tais princípios foram descritos como: "coesão, coerência, informatividade, situacionalidade, intertextualidade, intencionalidade e aceitabilidade" (Beaugrande; Dressler, 1981, apud $\mathrm{KOCH}, 2008$, p. 11).

0 primeiro desses princípios, a coesão textual, relacionase às diferentes possibilidades de conexão entre os elementos linguísticos na superfície textual. 0 trabalho aqui proposto concentra-se na área de pesquisa que se preocupa com o estudo dos elementos da língua que têm por função estabelecer relações textuais, ou seja, os recursos de coesão textual, enquanto elementos essenciais para a produção de sentidos no texto. Tais recursos são classificados, pela maioria dos pesquisadores, em dois grandes grupos que traduzem os movimentos de construção do texto: a coesão referencial ou referenciação (pela qual se dá a introdução de novos referentes e a remissão a elementos 
anteriores ou subsequentes no texto) e a coesão sequencial ou sequenciação (que se realiza de forma a garantir a continuidade de sentido no texto).

Sendo o texto nosso objeto amplo de estudo e considerando que os textos emergem de situações concretas de interação social, não há como não reconhecer sua filiação a um gênero discursivo. Assim, consideraremos, neste trabalho, o conceito bakhtiniano de gênero do discurso na assimilação que esse conceito recebeu nos estudos desenvolvidos por Koch e Marcuschi'. Tomaremos por base os estudos desses autores tanto no que diz respeito aos gêneros discursivos, quanto no que se refere à área da linguística textual.

Para que a pesquisa fosse possível, dentro desse contexto, elencamos como objeto específico de estudo o emprego das expressões nominais como recurso de coesão textual em textos do gênero artigo de opinião.

As expressões nominais apresentam-se como formas linguísticas minimamente compostas por um núcleo (substantivo), acompanhado ou não de determinantes (artigos, pronomes adjetivos, numerais) e modificadores (adjetivos, locuções adjetivas, orações adjetivas). Na atividade de referenciação, tanto as expressões nominais definidas quanto as indefinidas ${ }^{2}$ podem efetuar uma seleção, dentre as características de um referente, daquelas relevantes para produzir o sentido conforme os objetivos do produtor do texto, o que as torna uma das formas mais ricas de progressão textual, bem como um importante instrumento na construção da orientação argumentativa de um texto.

Conforme afirmado anteriormente, para a linguística textual, o texto deve ser considerado a unidade básica de sentido em uma situação de comunicação e, portanto, é importante ressaltar o fato de que todo texto é produzido por um sujeito social, que faz parte de determinada cultura em certa época, ou seja, "um texto se dá numa complexa relação interativa entre a linguagem, a cultura e os sujeitos históricos que operam nesses contextos" (Marcuschi, 2008, p. 93).

Considerando-se a relação postulada por Marcuschi, entendese que o sujeito atribui sentidos aos referentes introduzidos em um texto a partir de seu universo cultural. Assim, cada referente torna-se um produto da prática social. Segundo Koch, (2004, p. 51),
1. Nessa acepção, "gêneros textuais são os textos que encontramos em nossa vida diária e que apresentam padrões sociocomunicativos característicos definidos por composições funcionais, objetivos enunciativos e estilos concretamente realizados na integração de forças históricas, sociais, institucionais e técnicas" (Marcuschi, 2008, p. 155). Alguns exemplos de gêneros seriam: bilhete, reportag'em, receita culinária, bula de remédio, e-mail, conto, entre outros.

2. As expressões nominais definidas e indefinidas diferenciam-se por seu determinante. As definidas são iniciadas por um determinante definido (artigo definido ou pronome demonstrativo, por exemplo); já as indefinidas podem ser marcadas pela ausência de um determinante ou por um determinante indefinido (como um artigo ou pronome indefinido). 


\begin{abstract}
[...] o que julgamos ser a realidade não passa de um produto de nossa percepção cultural. Ou seja, percebemos os objetos tal como previamente definidos por nossas práticas culturais: a "realidade" é fabricada por toda uma rede de estereótipos culturais, que condicionam a própria percepção e que, por sua vez, são garantidos e reforçados pela linguagem, de modo que o processo de conhecimento é regulado por uma interação contínua entre práxis, percepção e linguagem.
\end{abstract}

Dessa forma, o referente não é visto como uma simples representação do mundo, mas como um produto da percepção e da cogniç̧̃ao do sujeito.

Tecnicamente, a referenciação diz respeito às diferentes formas de introdução e retomada de referentes em um texto. No entanto, voltando à ideia de que os referentes não são meramente rótulos que têm por função identificar aquilo a que se referem, mas constituem-se como objetos de discurso construídos e reconstruídos no próprio discurso, a partir da percepção de mundo, da experiência cultural e dos objetivos de comunicação de cada sujeito, a referenciação assume papel discursivo e, portanto, não neutro. A partir do material linguístico que tem à disposição, o sujeito realiza escolhas que produzem efeitos de sentidos. Como a atividade de referenciação se insere nessa produção, logo também implica produção de sentidos.

Como afirmam Koch e Elias (2009a, p. 124), "as formas de referenciação são escolhas do sujeito em interação com outros sujeitos, em função de um querer-dizer", o que nos conduz a considerar a atividade de referenciação como aspecto fundamental para a estruturação do discurso argumentativo, o qual é produzido com a intenção de fazer com que o interlocutor compartilhe de suas opiniões.

$\mathrm{Na}$ atividade de referenciação, quando os referentes são retomados ou servem de base para a introdução de novos referentes, as formas ou expressões nominais assumem papel de destaque pelo fato de propiciarem uma ampla gama de escolhas lexicais, o que influi diretamente na estruturação do discurso que se pretende produzir, visto que tais escolhas determinarão a construção e a reconstrução dos referentes ao longo do processo de produção discursiva, interferindo na progressão temática e na argumentação.

Dessa forma, a escolha do artigo de opinião como gênero textual base para nosso estudo justifica-se, primeiramente, pela orientação argumentativa que as expressões nominais podem 
assumir em um texto e, em segundo lugar, pela necessidade de estruturação do discurso argumentativo de alunos da educação básica, o que é de fundamental importância para a plena participação na vida social pública: ter a possibilidade de expressar seus pontos de vista e sustentá-los com justificativas e argumentos consistentes constitui-se como instrumento para o pleno exercício da cidadania.

A necessidade a que nos referimos foi constatada tanto a partir de nossa experiência docente com diferentes anos do ensino fundamental II, quanto por pesquisas e estudos já realizados. Leal e Morais (2006, p. 8), a esse respeito, comentam:

\footnotetext{
[...] diversos autores têm se debruçado sobre as questões relativas aos processos de desenvolvimento das capacidades de defender pontos de vista. São comuns, no tocante a essa temática, depoimentos de educadores e resultados de estudos que apontam dificuldades na produção de textos escritos por crianças, adolescentes e adultos quando buscam argumentar.
}

Assim sendo, como professores de língua portuguesa, acreditamos ser pertinente não só formar os alunos quanto ao conhecimento que lhes possibilite ter pontos de vista bem fundamentados, mas também relativamente ao domínio dos recursos da língua escrita que lhes possibilitem participar da produção de discursos argumentativos, os quais são base de grande parte das interações sociais.

Partindo dos pressupostos anteriormente apresentados com relação ao estudo da língua e da necessidade diagnosticada, o objetivo que orienta esta pesquisa é: investigar a maneira pela qual se dá o processo de referenciação construído pelo emprego de expressões nominais no corpus selecionado com o propósito de apontar alternativas didáticas para o tratamento do assunto no ensino de língua portuguesa.

\section{A pesquisa}

A fim de alcançar o objetivo desta investigação, inicialmente, selecionamos um corpus composto por um conjunto de seis artigos de opinião - escritos por diversos jornalistas - que circularam na grande imprensa em torno de temas diferentes: as catástrofes naturais e o uso da energia atômica e a proposição de plebiscitos sobre o comércio de armas de fogo e munição.

Esclarecemos que a opção por analisar artigos de opinião 
escritos por jornalistas pautou-se justamente na possibilidade de observar o funcionamento efetivo de um recurso linguístico, o que pode dar indicações do que ensinar a partir da identificação da variedade linguística utilizada de fato. Além disso, a seleção de artigos que abordavam temas diferentes foi feita com o propósito de investigar se a temática abordada interferiria nas funções assumidas pelas expressões nominais.

Após a constituição do corpus, passamos à sua análise, a qual consideramos pertinente realizar em duas etapas distintas: a primeira diz respeito à análise quantitativa dos dados e a segunda, à análise qualitativa.

$\mathrm{Na}$ análise quantitativa dos dados, procuramos verificar quais das funções cognitivo-discursivas assumidas pelas expressões nominais são mais recorrentes nos artigos de opinião. Já na análise qualitativa, buscamos compreender os cruzamentos de funções cognitivo-discursivas mais frequentes e os efeitos de sentido daí decorrentes, quando as expressões nominais assumiam mais de uma função.

Por meio dessa metodologia de pesquisa, acreditamos ser possível obter indícios sobre alguns recursos linguísticos que podem ser explorados em sala de aula para a instrumentalização dos alunos para a produção escrita do discurso argumentativo. Dessa forma, para concluir a pesquisa, pretendemos apresentar algumas indicações para o ensino de língua portuguesa que possam configurar-se como alternativas às abordagens tradicionais.

\section{Funções cognitivo-discursivas das expressões nominais}

Procuraremos demonstrar, por meio de exemplos retirados do corpus analisado para a realização deste trabalho, as funções cognitivo-discursivas assumidas pelas expressões nominais em artigos de opinião. Observamos que as categorias apresentadas a seguir foram definidas a partir dos estudos apresentados por Koch (2004), Koch e Elias (2009a, 2009b) e Abreu (2010).

\subsection{Orientação argumentativa}

Em textos argumentativos, é muito comum o emprego de expressões nominais, com caráter metafórico ou não, a fim de constituir a orientação argumentativa ${ }^{3}$. 0 emprego das expressões
3. Koch (2004) e Koch e Elias (2009b) postulam a orientação argumentativa como uma das funções cognitivo-discursivas desempenhadas pelas expressões nominais. Neste estudo, entendemos que as funções cognitivo-discursivas das expressões nominais (descritas a seguir) podem ou não estar a serviço da orientação argumentativa do texto. 
nominais definidas e indefinidas, nas diferentes funções cognitivodiscursivas que podem desempenhar, configura-se como um recurso significativo para "levar o leitor em direção às conclusões desejadas, isto é, para que o leitor apreenda a orientação argumentativa do texto" (Koch; Elias, 2009b, p. 154).

No parágrafo a seguir, nota-se o emprego de duas expressões nominais que concorrem para a orientação argumentativa do texto:
Queremos continuar correndo esses riscos? Apesar de termos alternativas mais promissoras, como a energia solar e a eólica? Essas são energias renováveis, que nos tornam independentes do petróleo, que não oferecem perigo, que são sustentáveis e que não comprometem as gerações futuras. É nessas energías que devemos investir. Elas não são um sonho ambientalista. Elas representam uma sociedade limpa, sustentável e moderna. (Deutsche Welle, 2011, grifo nosso)

Ao analisar o trecho transcrito, nota-se que ambas as expressões em destaque contribuem para a estruturação do discurso argumentativo na medida em que avaliam positivamente outros tipos de energia, em detrimento da nuclear. A partir desse exemplo e daqueles que serão mostrados adiante, buscaremos evidenciar como as formas nominais referenciais desempenham um papel de relevância na progressão textual e na construção dos sentidos.

\subsection{Ativação/reativação na memória}

As expressões nominais, ao introduzir um referente no texto, operam uma ativação, na memória dos interlocutores, das características desse referente que o locutor procura destacar, como vemos no seguinte exemplo: "A catástrofe nuclear no Japão vai mudar o mundo, e de forma permanente. Ela deixa claro o quão perigosa e incontrolável a energia atômica de fato é" (Deutsche Welle, 2011, grifo nosso).

Nesse trecho, a expressão nominal definida em destaque não só introduz o referente, como também destaca para o leitor a opinião do produtor do texto sobre o acidente nuclear no Japão. A seleção de "catástrofe" como núcleo da expressão nominal avalia os acontecimentos como desastrosos, de grandes proporções, atribuindo força argumentativa ao texto. 


\subsection{Recategorização de referentes}

Algumas vezes, ao retomarem um referente anteriormente introduzido no texto, as expressões nominais operam uma recategorização desse referente, agregando novas informações ao que foi apresentado inicialmente. Observemos:

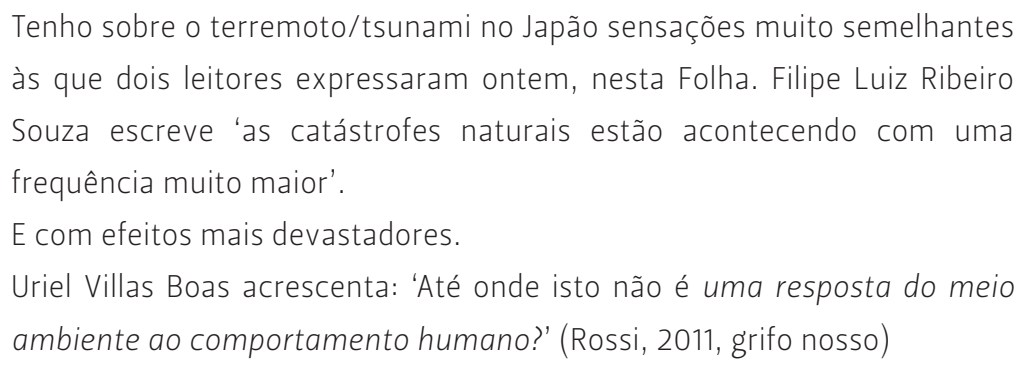

A expressão nominal indefinida em destaque opera uma recategorização do referente "as catástrofes naturais", acrescentando nova informação e fazendo com que o leitor pense no referente sob outro aspecto.

\subsection{Encapsulamento e rotulação}

Na construção da progressão textual, pode-se sumarizar um trecho anterior ou posterior do texto empregando uma forma pronominal ou nominal.

Quando, para isso, emprega-se um pronome demonstrativo neutro (isto, isso, aquilo), temos o que se denomina encapsulamento. Observando novamente o trecho usado como exemplo no item anterior, nota-se que o pronome demonstrativo "isto" (no $3^{\circ}$ parágrafo do excerto) sumariza os dois parágrafos anteriores, caracterizando o fenômeno explicado.

Quando, no entanto, a sumarização é feita por meio de uma expressão nominal, temos o que se denomina rotulação. No exemplo a seguir, observa-se como a expressão "esses riscos" sumariza informações apresentadas no parágrafo antecedente:

Além disso, o perigo não reside apenas nas panes - também o lixo radioativo, para o qual ninguém tem um destino adequado, vai um dia se tornar um obstáculo. Até hoje não existe em nenhum país do mundo um lugar adequado para depositar detritos atômicos, apesar de buscas intensas.

Queremos continuar correndo esses riscos? (Deutsche Welle, 2011, grifo nosso) 
No caso em análise, podemos notar que a expressão nominal "esses riscos" rotula as informações precedentes de maneira não neutra, pois categoriza as situações descritas como probabilidades de perigo, o que deixa clara sua orientação argumentativa.

\subsection{Retomada e explicação de termos por meio de sinonímia, hiperonímia ou definição de termos}

Quando, ao introduzir um referente, o locutor julga que o termo utilizado para isso é pouco usual ou muito específico, ele pode recorrer ao uso de um sinônimo mais comum ou de um hiperônimo (termo de sentido mais amplo, que engloba o termo mais específico) ou, ainda, apresentar uma definição ou um esclarecimento para auxiliar seu interlocutor no entendimento do texto. Vejamos:

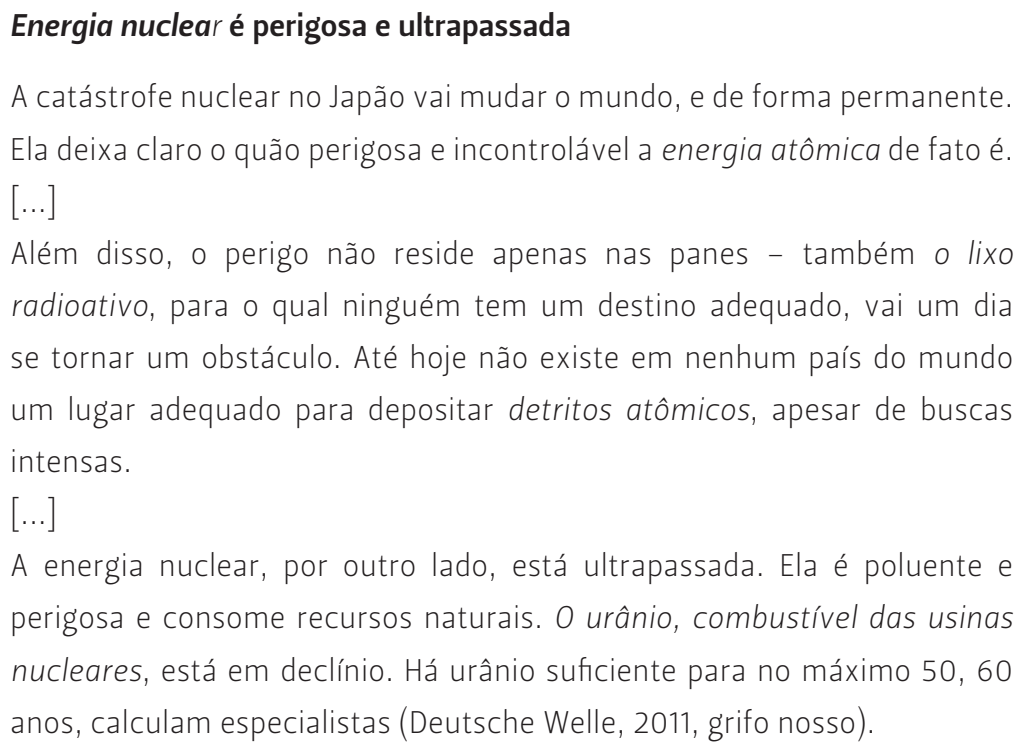

No primeiro parágrafo, o termo "energia atômica" retoma por hiperonímia a expressão "energia nuclear" apresentada no título do texto, posto que a energia nuclear é um tipo de energia atômica. Na sequência, pode-se observar que a expressão nominal definida "o lixo radioativo", novo referente introduzido, é, no mesmo parágrafo, retomada por "detritos atômicos", configurando uma retomada por sinonímia. Ainda no último trecho transcrito, notamos uma explicação por meio de definição de termo: a expressão "combustível das usinas nucleares" define o termo "urânio", explicando-o.

No texto em análise, observamos que, por meio dos recursos linguísticos destacados no exemplo, o locutor consegue 
demonstrar aos leitores o conhecimento que possui acerca do assunto, pois usa termos específicos do campo lexical relacionado à energia nuclear e, ainda, explica o significado desses termos.

\subsection{Especificação por meio da sequência hiperônimo/hipônimo}

Ao considerar necessário um maior refinamento da categorização atribuída a um referente, o locutor pode recorrer ao que se denomina anáfora especificadora, uma anáfora constituída por hiperônimo e hipônimo(s), como no exemplo seguinte:

\footnotetext{
Os leigos temos apenas de aceitar que, por qualquer motivo - como um tremor - , o famoso núcleo ganhe vida, ferva, fuja ao controle e contamine tudo em volta. Difícil é entender por que essas usinas são construídas justamente em lugares sujeitos a calamidades, como os terremotos, os tsunamis e a inconsequência humana. (Castro, 2011, grifo nosso)
}

No trecho transcrito, observamos uma especificação por meio da sequência hiperônimo/hipônimo, introduzida pelo termo genérico "calamidades", especificado por "os terremotos", "os tsunamis" e "a inconsequência humana". Esse trecho é iniciado pela expressão nominal definida "os leigos", o que qualifica o enunciador como alguém que não é especialista no assunto tratado. No entanto, esse recurso leva o leitor a entender que não é necessário ser especialista no assunto para se prever as consequências possíveis ao se construir usinas nucleares em locais sujeitos a fenômenos geográficos como terremotos e tsunamis.

\subsection{Retomada por meio de meronímia}

Por vezes, ao retomar um referente, o produtor do texto utiliza-se de um termo merônimo, ou seja, um termo semanticamente relacionado ao referente, mas que denota uma de suas partes. A esse fenômeno denomina-se meronímia. Vejamos:

\footnotetext{
O filme, de 1979, todo mundo viu ou assistiu depois, pela TV: 'A Síndrome da China'. Um engenheiro, uma repórter e um cinegrafista (Jack Lemmon, Jane Fonda, Michael Douglas) denunciam um acidente numa usina nuclear na Califórnia: um abalo quase imperceptível expôs o núcleo do reator, provocando um superaquecimento capaz de fundi-lo e romper a proteção de aço e concreto, gerando um calor que pode atravessar a crosta do planeta, explodir e espalhar radiação (Castro, 2011, grifo nosso).
} 
Nesse parágrafo, nota-se que à expressão nominal "uma usina nuclear" associam-se outras duas - "o núcleo do reator" e "a proteção de aço e concreto" -, que denominam partes de uma usina. Dessa forma, configura-se a construção de uma cadeia anafórica em que a retomada é realizada por meio de meronímias.

\subsection{Introdução ou retomada por meio de metáforas}

A metáfora é uma figura de linguagem que se caracteriza pela transposição de sentido de um termo para outro, configurando uma comparação implícita. As expressões nominais definidas e indefinidas são comumente empregadas para a construção de metáforas, como se vê a seguir:
Argumentar que o Japão conhece o barril de pólvora sobre o qual está sentado, e que terremotos como o atual não acontecem na Alemanha, é simplificar as coisas. E se um avião cair sobre uma central? E quanto aos ataques terroristas, às múltiplas falhas técnicas ou humanas? (Deutsche Welle, 2011, grifo nosso)

A expressão nominal "o barril de pólvora" funciona como uma metáfora relacionada às características geográficas do território japonês.

Segundo Abreu (2010, p. 51), a metáfora "acrescenta um aspecto emocional àquilo que falamos, ao trabalhar com imagens" e, ainda, exerce função argumentativa.

\subsection{Categorização metaenunciativa de um ato de enunciação}

Por meio do uso de expressões nominais, é possível introduzir em um texto o que Apothelóz chama de "objetos clandestinos" (Apothelóz, 1995 apud Koch, 2004, p. 78). Tal ação consiste em apresentar - metaenunciativamente - uma categorização ou avaliação de um ato de enunciação realizado, como no exemplo seguinte:

Minha dúvida é se a frequência (e as consequências) é de fato maior ou o volume de informações é que aumentou exponencialmente nos últimos 20 ou 30 anos, sei lá.

Uma vez, um acadêmico cujo nome me escapa agora escreveu que a notícia da morte de Abraham Lincoln levou 13 dias para chegar à Europa. Hoje, a notícia sobre o terremoto no Japão, do outro lado do mundo, leva segundos para estar na tela do seu computador ou da sua televisão. 
Pode ser, portanto, que as tragédias acontecessem, antes, em locais distantes da nossa aldeia original, sem que delas tomássemos conhecimento. Hoje, é impossível escapar desse tsunami informativo.

Mesmo fazendo essa ressalva, não há como fugir à sensação de que a coisa está esquisita. Na semana passada, na fria Suiça, fazia um friozinho até agradável, mas na "quente" Espanha nevava em quantidades industriais (Rossi, 2011, grifo nosso).

Nesse trecho, a expressão "essa ressalva" refere-se às informações apresentadas nos três parágrafos anteriores, categorizando-as como uma ressalva e, portanto, configurandose como uma categorização metaenunciativa de um ato de enunciação realizado.

\subsection{Criação de frames e scripts}

As expressões nominais podem também contribuir para a criação de frames e scripts em um texto. Um frame, segundo Abreu (2010, p. 37), constitui-se por um "domínio semântico vinculado a uma palavra". Esse domínio pode ser formado tanto por elementos tipicamente relacionados a determinada palavra, quanto por elementos vinculados à imaginação ou à cultura. Vejamos os trechos a seguir:

\footnotetext{
Oportunismo, teu nome é Congresso. O presidente do Senado, José Sarney (PMDB - AP), propôs ontem um plebiscito sobre o uso de armamento no país. Se aprovado, o projeto determina a realização de uma consulta popular em outubro deste ano.

A pergunta: 'O comércio de armas de fogo e munição deve ser proibido no Brasil?'.

Em 2005, a população já havia sido consultada. A decisão de $64 \%$ foi a de não vetar o comércio de armas no país. Não vou entrar aqui no mérito de proibir ou não a venda de armamentos. Prefiro tratar da forma de reação espasmódica dos congressistas em momentos de grande comoção popular."

$[\ldots]$

"O oportunismo do Congresso desconsidera a realidade. 0 fato de que proibir o comércio legal de armas no país não impedirá assassinos potenciais de continuar a obter, com certa facilidade, os revólveres usados em seus crimes" (Rodrigues, 2011, grifo nosso).
}

As expressões em destaque nos trechos transcritos referemse todas ao frame do comércio de armas, contribuindo para que o leitor, nesse contexto, pense em diversas outras situações 
relacionadas à que está sendo descrita e verifique que a tese do artigo é válida.

Como se pode verificar, a constituição de um frame está relacionada à construção de sequências textuais descritivas e/ou expositivas; já um script relaciona-se à construção de sequências narrativas justamente por constituir-se por "uma ordenação cronológica dos elementos de um frame" (Abreu, 2010, p. 40), como um roteiro para determinada situação, que já é esperado em certa cultura. Vejamos:

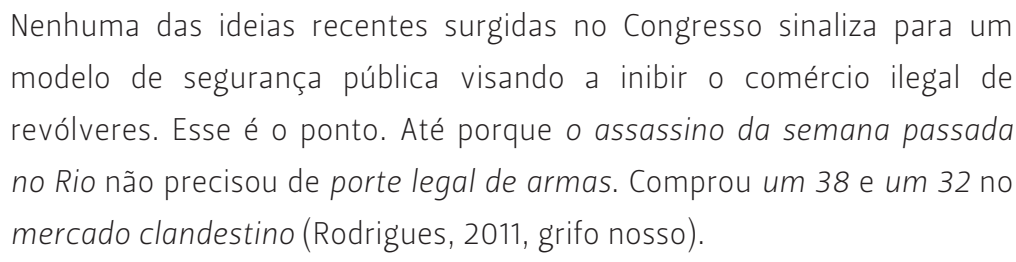

Nesse trecho, pode-se identificar a criação de um script, visto que é de conhecimento do senso comum a possibilidade de se adquirir um revólver no mercado clandestino sem a posse de porte legal de armas e, portanto, a ação do referido criminoso seguiu um roteiro esperado, possível de ser imaginado. A criação desse script também concorre para a validação da tese defendida pelo articulista.

\section{0 uso das expressões nominais em artigos de opinião}

Após a verificação de como as expressões nominais assumem funções cognitivo-discursivas em artigos de opinião, consideramos pertinente realizar uma análise quantitativa dos dados obtidos de forma a buscar indícios sobre quais recursos linguísticos poderiam ser mais explorados na instrumentalização dos alunos para a produção escrita do discurso argumentativo.

Na tabela 1, pode-se observar o total de ocorrências de cada função cognitivo-discursiva desempenhada pelas expressões nominais nos textos analisados em dados percentuais. 
Tabela 1 - Percentual das funções cognitivo-discursivas em relação ao total de expressões nominais nos textos analisados

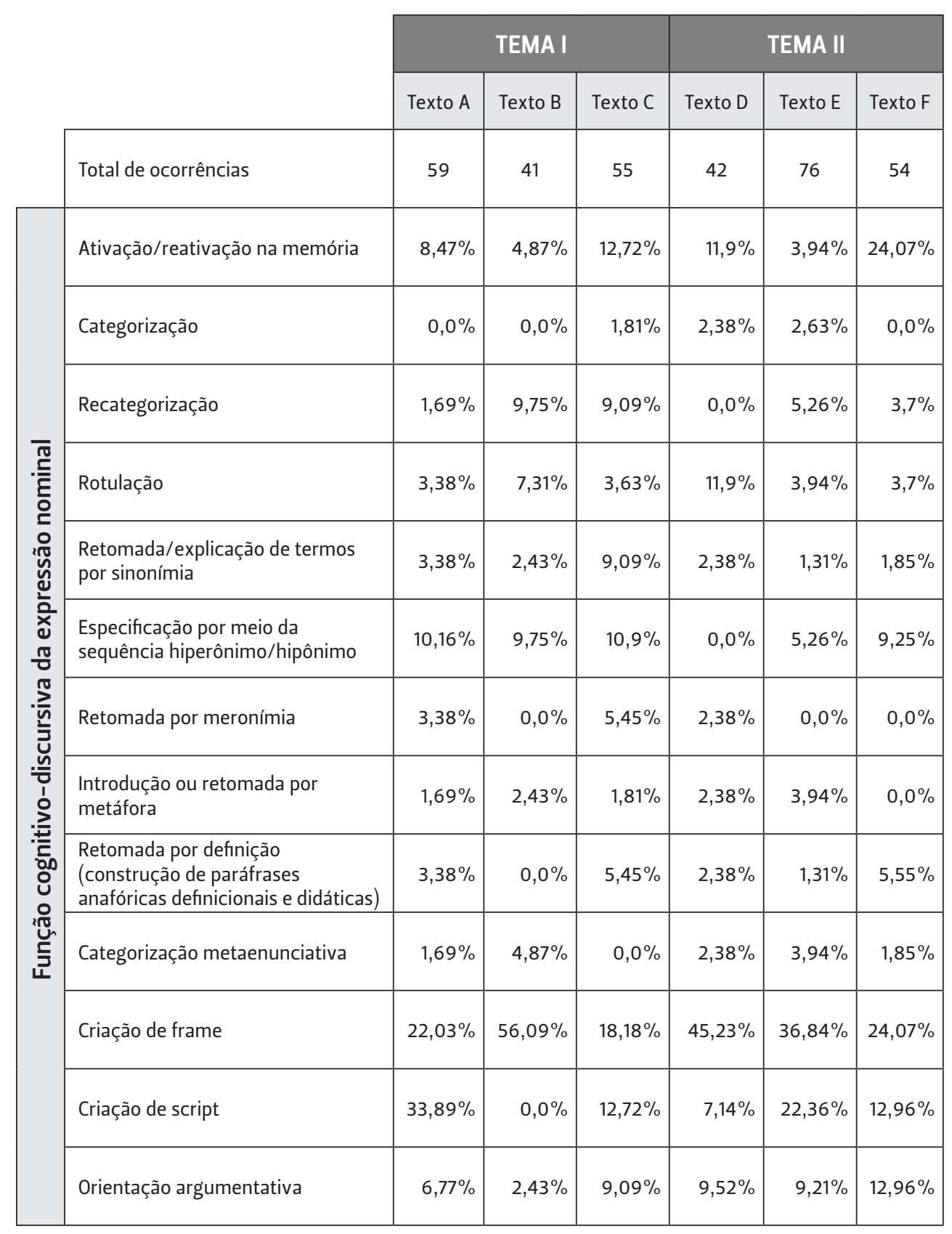

De acordo com a análise quantitativa realizada, nota-se, primeiramente, que as expressões nominais definidas e indefinidas são realmente recorrentes em textos do gênero artigo de opinião, mais especificamente, em sequências textuais argumentativas.

Com relação à influência do tema nos tipos de funções assumidas pelas expressões nominais empregadas nos textos, notamos algumas diferenças entre os tipos de funções cognitivo- 
discursivas mais recorrentes nos textos de cada grupo temático. Nos textos do tema I, houve maior recorrência de expressões nominais que desempenharam funções relacionadas à sinonímia, à hiperonímia e à meronímia. Entendemos que, talvez, isso se dê justamente por se tratar de um assunto que envolve, de certa forma, o uso de termos técnicos relacionados ao funcionamento das usinas nucleares (o que pode ser um complicador para o entendimento do texto, caso o leitor não possua esse conhecimento); por isso, a fim de auxiliar o leitor no entendimento do texto, talvez os autores tenham realizado um número maior de operações de retomada com o emprego de termos sinônimos, hiperônimos e merônimos se compararmos aos textos do tema II.

Por outro lado, observa-se que, nos textos do tema II, é maior a recorrência de expressões nominais com função cognitivodiscursiva de orientação argumentativa. Isso pode ter ocorrido pelo fato de esse tema retomar uma discussão já realizada anteriormente, com o referendo de 2005 sobre a comercialização de armas de fogo e munição, ou justamente por envolver a aprovação ou a rejeição de medidas que afetariam a vida da sociedade brasileira, o que incitaria o debate.

Consideramos interessante observar, ainda, que as expressões nominais desempenham, em cada texto analisado, a maioria das funções cognitivo-discursivas descritas, o que nos demonstra que, nos processos de referenciação dos quais fazem parte, essas formas nominais referenciais estão muito além de funcionar somente como sinônimos na construção de cadeias anafóricas.

Ao observarmos os dados, é notável a porcentagem de expressões nominais que operam para a criação de frames (de $18,18 \%$ a $56,09 \%$ ) em todos os textos analisados. Com relação à constituição de frames, é interessante notar que algumas das expressões nominais que os compõem desempenham mais de uma função cognitivo-discursiva ao mesmo tempo. Talvez, ao assumir esse caráter multifuncional, as expressões nominais operem em conjunto para o cumprimento de diferentes objetivos: indicar pontos de vista, apontar direções argumentativas, facilitar o acesso ao referente, entre outras. A verificação de que as expressões nominais poderiam acumular mais de uma função ao mesmo tempo levou-nos a submeter o corpus a uma análise qualitativa para observar exatamente o cruzamento dessas funções, o que resultou na tabela 2. 
Tabela 2 - Ocorrências de expressões nominais com duplas-funções discursivo-argumentativas

\begin{tabular}{|c|c|c|c|c|c|c|c|c|c|}
\hline \multicolumn{2}{|c|}{ DUPLAS-FUNÇÕES } & \multirow{2}{*}{ 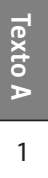 } & \multirow{2}{*}{ 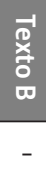 } & \multirow{2}{*}{ 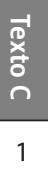 } & \multirow{2}{*}{ 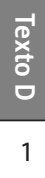 } & \multirow{2}{*}{ 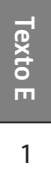 } & \multirow{2}{*}{ 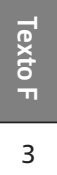 } & \multirow{2}{*}{$\frac{\stackrel{-1}{\text { ते }}}{7}$} & \multirow{2}{*}{$\frac{\circ}{18,42 \%}$} \\
\hline Ativação na memória & Orientação argumentativa & & & & & & & & \\
\hline Ativação na memória & Frame & - & - & 3 & - & - & 1 & 4 & $10,52 \%$ \\
\hline Ativação na memória & Categorização & 1 & - & - & - & - & - & 1 & $2,63 \%$ \\
\hline Ativação na memória & Rotulação & - & - & - & - & - & 1 & 1 & $2,63 \%$ \\
\hline Rotulação & Frame & 2 & 1 & - & 1 & - & - & 4 & $10,52 \%$ \\
\hline Rotulação & Script & - & - & - & 1 & - & - & 1 & $2,63 \%$ \\
\hline Rotulação & Orientação argumentativa & - & - & - & - & 2 & - & 2 & $5,26 \%$ \\
\hline Hiperônimo & Frame & 1 & 1 & - & - & - & - & 2 & $5,26 \%$ \\
\hline Hiperônimo & Orientação argumentativa & 1 & - & - & - & - & - & 1 & $2,63 \%$ \\
\hline Metáfora & Frame & 1 & 1 & - & - & - & - & 2 & $5,26 \%$ \\
\hline Metáfora & Orientação argumentativa & - & - & 1 & 1 & 2 & - & 4 & $10,52 \%$ \\
\hline Metáfora & Script & - & - & - & - & 1 & - & 1 & $2,63 \%$ \\
\hline Recategorização & Orientação argumentativa & - & 1 & 3 & - & 1 & 1 & 6 & $15,78 \%$ \\
\hline Recategorização & Frame & - & - & 1 & - & - & - & 1 & $2,63 \%$ \\
\hline Sinonímia & Orientação argumentativa & - & - & - & - & 1 & - & 1 & $2,63 \%$ \\
\hline & & & & & & & & 38 & $100 \%$ \\
\hline
\end{tabular}

A partir da observação da tabela 2 , notamos que não só na constituição de frames as expressões nominais acumulam funções: de um total de 327 ocorrências, em 11,62\% dessas situações discursivas, ocorre uma dupla-função.

É interessante pontuar que nem todas as funções cognitivodiscursivas apresentaram esse caráter acumulativo. As funções cognitivo-discursivas que se associam a outras com mais frequência são o frame e a orientação argumentativa.

Todas essas funções e estratégias que se dão durante a atividade de referenciação operam para que se atribua coesão a um texto e, ademais, mantêm estreita relação com o estabelecimento da coerência textual, visto que "os dois grandes movimentos responsáveis pela estruturação do texto - o de retrospecção e o de prospecção -, realizados em grande parte por recursos coesivos, são determinantes para a produção de sentidos" (Koch, 2004, p. 46). 
Sendo assim, acreditamos que a ocorrência de expressões nominais definidas e indefinidas e a diversidade de funções cognitivo-discursivas que assumem nos textos analisados indicam-nos que tais expressões realmente se constituem como um significativo recurso de coesão para a progressão referencial na construção de diferentes sequências textuais.

\section{Considerações finais}

0 trabalho que desenvolvemos buscou investigar como as expressões nominais contribuem para o processo de referenciação em artigos de opinião, de forma a indicar algumas possibilidades para a exploração dos recursos de coesão referencial especialmente, as expressões nominais - em sala de aula.

A partir dos dados observados e da análise realizada, foi possível constatar a relevância das expressões nominais referenciais para a progressão textual e para a construção dos sentidos dos textos que produzimos e daqueles que buscamos compreender.

0 estudo das expressões nominais como recursos de coesão e de argumentação proporciona a efetiva ampliação do saber linguístico dos educandos, uma vez que possibilita tanto a análise da textualidade, quanto a estruturação do discurso argumentativo. Assim, a abordagem desse conteúdo constitui-se como uma importante estratégia para o desenvolvimento das habilidades de leitura e de produção de textos dos alunos nas aulas de língua portuguesa.

Nesse sentido, tanto no trabalho com compreensão leitora, quanto com produção textual, é importante desenvolver com os alunos atividades que propiciem a percepção de como as estratégias de referenciação e os diferentes objetivos do autor ao empregar expressões nominais referenciais implicam a produção de sentidos, tornando-os capazes de depreender os sentidos produzidos a partir do emprego dessas expressões.

Para tanto, apontamos, inicialmente, o trabalho com o léxico como uma interessante possibilidade para o desenvolvimento das habilidades pretendidas. Contudo, acreditamos ser pertinente que esse trabalho não se centre apenas na exploração da sinonímia como meio para a ampliação do vocabulário. A hiperonímia e a meronímia também se constituem como recursos significativos para a progressão referencial e, portanto, explorá-las com os alunos possibilitaria, além da ampliação do vocabulário, 
a compreensão de como elas funcionam na estruturação do discurso.

A investigação do processo de composição e funcionamento de frames e scripts poderia configurar-se como uma estratégia didática para a percepção e a compreensão de esquemas que estruturam o texto e o discurso e que contribuem para a síntese semântica necessária ao estabelecimento da coerência textual.

Além disso, seria interessante analisar os efeitos de sentido obtidos com os constituintes das próprias expressões nominais presentes em um texto: o efeito de ser uma expressão definida ou indefinida; o efeito da presença de um núcleo constituído por um substantivo mais ou menos marcado discursivamente; o efeito provocado pela troca de um substantivo ou adjetivo por um sinônimo; ou o efeito obtido pela supressão de um dos modificadores, por exemplo. Outra possibilidade seria analisar o efeito provocado pela troca de uma expressão nominal inteira em função da posição do enunciador.

Durante o desenvolvimento de atividades que explorassem as noções apontadas anteriormente, também seria fundamental demonstrar aos alunos como as expressões nominais podem constituir-se como um importante recurso para guiar o leitor às conclusões desejadas, ou seja, para esclarecer a orientação argumentativa do texto. Nesse sentido, em estudo sobre a função discursiva dos elos coesivos referenciais, Cavalcante (2003, p. 8) observa "que a coesão firmada por elos lexicais costuma recategorizar referentes, somando significados e atributos e principalmente - veiculando pontos de vista do enunciador, o que Ihes dá enorme força argumentativa".

Considerando que o emprego de expressões nominais definidas e indefinidas em um texto configura-se como um recurso linguístico que possibilita amplamente a estruturação do discurso argumentativo, pensamos que, por meio de atividades que proponham o estudo das diferentes funções cognitivo-discursivas exercidas por essas expressões, os aprendizes não só realizariam leituras mais competentes, como também desenvolveriam importantes habilidades relacionadas à produção textual, tornando-se aptos a realizar escolhas significativas em função de seu querer-dizer, o que resultaria na produção de discursos mais eficientes nas diversas situações de interação verbal.

Em consonância com o que observamos, Biezus e Sella (s.d., p. 18), em artigo científico produzido a partir de pesquisa sobre 
coesão textual, referenciação e possíveis aplicações no ensino de língua portuguesa, afirmam que "a importância das formas referenciais na progressão textual e na construção de sentido dos textos é facilmente reconhecida, uma vez que são elas que estruturam o texto, que promovem a tessitura textual", apontando a importância das expressões referenciais para o ensino na área.

Por fim, ressaltamos que a análise realizada baseou-se em uma pequena amostragem, esclarecendo, ainda, que não tivemos a pretensão de suscitar conclusões definitivas. Destacamos a necessidade da realização de estudos complementares que contribuam para o aprofundamento das questões teóricas concernentes ao tema abordado, bem como investigações de caráter didático que permitam avaliar o impacto na ampliação das capacidades linguístico-discursivas de alunos de diferentes segmentos a partir da realização de atividades que se baseiem nos apontamentos aqui relacionados.

\section{REFERÊNCIAS}

ABREU, Antônio Suárez. Linguística cognitiva: uma visão geral e aplicada. São Paulo: Ateliê Editorial, 2010.

ANTUNES, Irandé. A coesão como propriedade textual: bases para o ensino do texto. Calidoscópio, v. 7, n. 1, p. 62-71, jan./ abr. 2009.

BEAUGRANDE, Robert de; DRESSLER, Wolfgang U. Introducción a la lingüística del texto. Tradução de Sebastián Bonilla. Barcelona: Editorial Ariel S.A., 1997.

BIEZUS, Marly de Fátima Gonçalves Tavares; SELLA, Aparecida Feola. A coesão textual na tessitura do texto: a referenciação como artifício de construção de objetos discursivos. s.d. Disponível em: <www.diaadiaeducacao.pr.gov.br/portals/ pde/arquivos/1163-4.pdf>. Acesso em: 28 ago. 2012.

CASTRO, Ruy. Síndrome da inconsequência. Folha de S. Paulo, São Paulo, 16 mar. 2011. Primeiro Caderno, Caderno A, p. 2.

CAVALCANTE, Mônica Magalhães. Função discursiva dos elos coesivos referenciais. 2003. Disponível em: <http://www. 
celsul.org.br/Encontros/05/pdf/153.pdf>. Acesso em: 28 ago. 2012.

DEUTSCHE WELLE. Energia nuclear é perigosa e ultrapassada. Correio do Brasil, Rio de Janeiro, 14 mar. 2011. Disponível em: <http://correiodobrasil.com.br/opiniao-energia-nuclear-eperigosa-e-ultrapassada/218714/>. Acesso em: 7 mai. 2011.

KOCH, Ingedore G. Villaça. Introdução à linguística textual: trajetória e grandes temas. São Paulo: Martins Fontes, 2004.

A coesão textual. 21. ed., 1. reimp. São Paulo:

Contexto, 2008.

KOCH, Ingedore G. Villaça; ELIAS, Vanda Maria. Ler e compreender: os sentidos do texto. 3. ed. São Paulo: Contexto, 2009a.

Ler e escrever: estratégias de produção textual. São Paulo: Contexto, 2009b.

LEAL, Telma; MORAIS, Artur Gomes. A argumentação em textos escritos: a criança e a escola. Belo Horizonte: Autêntica, 2006.

MARCUSCHI, Luiz Antonio. Produção textual, análise de gêneros e compreensão. São Paulo: Parábola Editorial, 2008.

NEVES, Maria Helena M. Gramática na escola. 5. ed. São Paulo: Contexto, 2001.

RODRIGUES, Fernando. Oportunismo. Folha de S. Paulo, São Paulo, 13 abr. 2011. Primeiro Caderno, Caderno A, p. 2.

ROSSI, Clovis. Tsunamis e cismas. Folha de S. Paulo, São Paulo, 13 mar. 2011. Primeiro Caderno, Caderno A, p. 2.

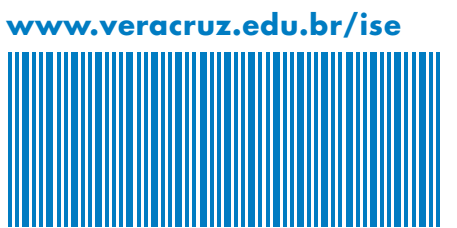

